\title{
Determinants of Attitudes and Perceptions on Resource Use and Management of Marsabit National Reserve, Kenya
}

\author{
Mohamed G. Shibia \\ Department of Natural Resources Management, Kenya Agricultural Research Institute National \\ Arid lands Research Centre, P.O. Box 147, Marsabit, Kenya \\ Telephone: 25469 2040, 254 722916149, Fax: 254692220 \\ E-mail: schibier@yahoo.com, mohamedshibia@gmail.com
}

KEYWORDS Attitude. Perceptions. Wildlife Damages. Benefits

\begin{abstract}
The establishment of protected areas had negative consequences on local communities. The shift in conservation resulted in restriction of access to resources, disruption of local culture and economies by tourists, increased predation on crops and livestock and displacement of inhabitants. A survey was undertaken to determine relationship between respondent's socio-economic characteristics and their attitudes and perceptions towards protected area conservation, determine the effect of wildlife benefits and their associated cost on attitudes and perceptions and determine if respondent attitudes and perceptions was affected by proximity of their residence to Marsabit National Reserve. One hundred eighty-seven households were selected through stratified random sampling and surveyed using questionnaire composed of both open and closed ended questions. Information acquired was triangulated through informal interviews, field observations and focused group discussions. Cross-tabulation using Pearson Chi-square test controlled for selected variables were used to determine differences between independent variables and attitudes. The sex and conservation awareness do not affect respondent attitudes while age, level of education, economic activities, wildlife benefits accrued and damages, restricted use of wildlife resources and distance from the reserve significantly affected the attitudes. In addition, age significantly affected the perceptions of the benefits accrued from the reserve while wildlife damage significantly related to economic activities. It is recommended to consider level of education, economic activities, and age of respondents and increase wildlife benefits to foster community based wildlife management.
\end{abstract}

\section{INTRODUCTION}

The creation of protected area is often considered a foreign concept and outgrowth of western conservation needs and values (Soto et al. 2001; Lusigi 1994; Akama et al. 1995; Fiallo and Jacobson 1995; Wells 1996; De Boer and Baquate 1998; Hough 1988). The concept was introduced to developing countries by colonial administrators and is presently being adopted and promoted by developing nations as commitment to various international conventions.

Imposing modern conservation paradigm and establishment of protected areas on local communities had received resistance from members of public and resulted to number of negative consequences including restriction of access to traditionally used resources, disruption of local culture and economies by tourists, increased depredation on crops and livestock by wild animals and, displacement of inhabitants from their traditional lands leading to social and cultural destructions. Due to the livelihood implications caused by protected area establishment local communities perceive it as a liability. Establishment and designation transform the area from primary provision of subsistence resources for local use to provision of aesthetic benefits (Lusigi 1981; Grove and Anderson 1987; Mishra 1994). In addition, local communities are vulnerable to the establishment of protected areas since they are followed by wildlife policies that restrict access to wildlife resources and their subsequent use. Wildlife numbers within the protected area has declined more than those outside the protected areas (DRSRS 1996) and those in Marsabit National Reserve (MNR) are most affected due to vast of the dispersal area.

Rapid population growth and change in local community values of wildlife as a resource, shift in land uses, attitudes and patterns of land ownership further make wildlife conservation unfeasible within and outside MNR (KWS 1994; Leitoro et al. 1994; Kirubi et al. 2000). The communities adjacent to MNR view wildlife as a liability and have negative attitudes towards it and the reserve. The intensity and magnitude of these conflicts are influenced by local people's negative attitudes and perceptions about wildlife. Negative attitudes towards wildlife and consequent land use changes will in the long run threaten the conservation and survival of wildlife outside protected 
areas, the integrity and viability of the reserves and, the biodiversity they are established to conserve (IUCN/UNEP 1987; Leitoro et al. 1994; Kirubi et al. 2000; Borgesio 2000). The different attitudes held may be due to socio-economic factors, levels of interaction between the local communities and MNR and the past experience with the wildlife. The success of wildlife conservation depends on the support of local communities living adjacent to a reserve and for community wildlife conservation to succeed an understanding of the attitudes and percep-tions of local communities is paramount. It is important to understand attitudes towards wildlife, the reserve and important factors that affect these attitudes and perceptions to improve tolerance for wildlife is of major conservation significance.

This study sought to (I) determine the effects of selected socio-economic factors (age, sex, level of education, economic activities) and conservation awareness on the attitudes and perceptions of the respondents' towards wildlife and protected area (PA), (II) effects of wildlife conservation benefits and their associated costs on attitudes and perceptions of respondents' and (III) if the respondents' attitudes and perceptions is affected by proximity to the reserve boundary.

\section{MATERIAL AND METHODS}

The study was conducted among the inhabitants of Marsabit National Reserve (MNR) within Marsabit District of northern Kenya. MNR was established in 1948 by Government of Kenya Notice No. 936 and located between latitude $01^{0}$ 152 North and $04^{\circ} 272$ North and longitude $36^{\circ}$ 032 East and $38^{\circ} 592$ East. Of the $78,078 \mathrm{~km}^{2}$ that form the total area of the district, $13,807 \mathrm{~km}^{2}$ has been set aside as wildlife and forest reserve, making the district potentially an important area nationally in terms of natural resource management under protection.

The MNR boundary was reduced significantly with the prevailing political circumstances to the present size of $2070 \mathrm{~km}^{2}$ on $22^{\text {nd }}$ December, 1960, and composed of the Marsabit Forest Reserve, which covers an area of $144 \mathrm{~km}^{2}$ (MPND 1994). An area of $360 \mathrm{~km}^{2}$ including the $80 \mathrm{~km}^{2}$ of the Forest Reserve is managed on a national park status while $540 \mathrm{~km}^{2}$ has been excised out of MNR for human settlement (Leitoroh et al. 1994).

The reserve is managed by both Forest Depart-ment and Kenya Wildlife Service under the Memorandum of Understanding. It plays an important ecological function as water catchments, dry season livestock grazing and serves as an important elephant habitat in Northern Kenya (IUCN/UNEP 1987). The area has a bimodal rainfall pattern and rainy seasons occur from March to April/May and October to December. However, this pattern is quite variable and generally low in most parts of the district. Mostly, it is unreliable and unevenly distributed in low-lying areas. The Forest Reserve has diverse plant communities due to their isolation and high rainfall compare to the surroundings. The tree species provide both timber and none timber forest products for the inhabitants and support livelihoods.

Agriculture has gained popularity among those communities who practice pastoralism, a land use practice that is traditionally compatible with wildlife conservation. Increased human population further increased demand for land in the district for food production. This has led to human encroachment into the important wildlife area intensifying wildlife/human conflicts (Leitoroh et al. 1994). Increased population exert pressure on the MNR, with an area of $540 \mathrm{~km}^{2}$ being excised from the reserve for crop cultivation and settlement. These areas have high agricultural potential and receive sufficient rainfall and the same area serve elephant migratory routes, hence, human-wildlife conflicts are rampant.

The stratified random sampling was used to select sample from those households residing within vicinity of the reserve. The distance from the reserve was stratified into $5 \mathrm{~km}$ to those over $15 \mathrm{~km}$ from the reserve boundary. Households were used as units of analysis because it is in the household that major decisions relating to resource use are made. The study took the form of a field survey based on selected households and key informants. The topographic map from the District Land and Survey Office was used to determine distance of households from the reserve boundary. Accessible roads, paths or tracks running along or perpendicular to the reserve boundary were taken to represent the stratum.

The area was divided into four stratified sampling units represented by the pre-determined categories of the distance from the reserve. This was based on distance of the household from the reserve boundary. Random selection was adopted within the categorized distance to ensure that the study population has equal chances of being represented in the study. All the respondents in 
the given strata were identified using the list of the Population Census (GoK 1999) and representative sample of 187 households, comprising $30 \%$ of target population was randomly selected from those households who have residency within the four strata using computer.

For each stratum the random numbers selected were used to make separate list representing the four strata. With the aid of this list and topographical map, which shows settlements around the reserve, the sample household in each stratum was identified and the head or the oldest member of the household present at the time of visit was interviewed. Wives are considered for the interview when their husbands are absent. In these communities husbands are heads of households while wives assume this role in the absence of their husbands. If both were absent, the oldest person in the household of, at least over 18 years of age was interviewed. In case none of three persons were available the interview was postponed.

The primary data were collected through administration of open and closed ended questionnaires. The questionnaire had three sections with information on demographic and socio-economic profile, perceptions of wildlife cost and benefits and attitudes and perceptions of wildlife conservation. The socio-economic factors recorded were sex, age, gender, year of formal education, source of income and involvement in conservation programs. The questions were asked to generate responses pertaining attitudes of the respondents. Validation on whether questionnaire could elicit the desired responses was achieved through a pre-test exercise during a reconnaissance study. In addition, personal interviews were conducted in crop fields and livestock grazing areas. The Borana, Rendille and Kiswahili languages were used as a means of communication. Key informants included local leaders (chief, assistant chief and headmen), KWS staff and representatives of Non Governmental Organization working in the area. Responses to the structured and open-ended questions were supplemented with field observations on various aspects of resource use, wildlife benefits and their associated costs. Secondary data was obtained from annual project reports, District Development Plans and statistical abstracts. The information collected was compared with the findings of the current study on how community perceives conservation projects. Responses to the structured questionnaires were supplemented with information from key informants.

The survey data was analyzed using the Statistical Package for Social Sciences (SPSS) Version 11.5 (SPSS, 1998), with level of significance set at $\mathrm{P}<0.05$. Cross-tabulation using Pearson Chi-Square test controlled for selected variables was used to determine the significance between independent variables and attitudes towards reserve.

\section{RESULTS}

\section{Demographic and Socio-Economic Profile of Respondents}

One hundred and eighty-seven respondents were interviewed. Of those interviewed one hundred and fifteen $(61.5 \%)$ and $72(38.5 \%)$ were males and females, respectively. Forty-eight respondents $(25.7 \%)$ were aged between 18-25 years, 50 respondents $(26.7 \%)$ were between 26 33 years, $46(24.6 \%)$ were between $34-41$ years and $41(21.9 \%)$ were above 41 years of age. This shows that $51 \%$ of the respondents were between the ages of 25-40 years representing most productive age group targeted for development.

Eighty-nine (47.6\%) of the respondents never went to school, 35 of respondents $(18.7 \%)$ attained primary level while 28 of respondents $(15 \%)$ have attained tertiary level of education. The literacy level is low among the respondents due to agropastoralism nature of the target communities. This has limited training opportunities for skilled labour and evidenced by minimal development opportunities in study area. They opted for informal occupation.

Results revealed that sixty-seven $(35.8 \%)$ of the respondents depend on crop farming, fortyeight of respondents $(25.7 \%)$ were agro-pastoralist, thirty-four (18\%) were pastoralists and thirty-eight of respondents $(20.3 \%)$ depended on other economic activities. Majority of the respondents were mixed farmers (agro-pastoralist) and this offers opportunity for adoption of National Development Policy for food security in the arid and semi-arid lands. However, it is inconsistent with wildlife conservation.

Results showed that fifty-nine $(31.6 \%)$ of the respondents lived less than five kilometres from the reserve boundary, fifty-four $(28.9 \%)$ between 5 -10 kilometres, thirty-eight $(20.3 \%)$ were found between 10 - 15 kilometres while thirty-six (19.3\%) 
of respondents reside more than 15 kilometres. This shows that population density in the areas adjacent to the reserve is high. This is attributed to the fertile land suited for crop farming and ease access to vital resources in the reserve. Both form reasons by adjacent community to encroach into the reserve.

\section{Local Perceptions of Wildlife Cost and Benefits Associated with MNR}

One hundred and seventy-four (93\%) of the respondents perceive the benefits of the reserve while thirteen $(7 \%)$ do not recognize the benefits of the reserve. One hundred and seventy nine $(95.7 \%)$ of the respondents reported incurring wildlife-induced damage while eight $(4.3 \%)$ do not. However, among those who incur wildlife damages, one hundred and forty-three (80\%) stated that the damages were not tolerable unlike thirty five of respondents (19.7\%). Similarly, one hundred and eighty (96.8\%) respondents had associated problems they encounter with the reserve while six of respondents (3.2\%) reported no problems with the reserve. One hundred and eighty-four (98.4\%) respondents reported that the reserve provides important resources while three $(1.6 \%)$ did not perceive the reserve as of any importance to them. Of those who reported the existence of resources in the reserve, sixty-nine (36.9\%) supported restricted use while one hundred and eighteen $(63.1 \%)$ rejected and they claim access to their resources are denied.

One hundred and sixty four $(87.7 \%)$ respondents were not aware of conservation awareness programs going on in the area while twenty three $(12.3 \%)$ agreed with existence of such programs. Responding to the question on attitudes towards wildlife conservation, findings showed that one hundred and thirty-nine (74.3\%) respondents perceives conservation as a waste of land and opted that the area covered by the reserve be converted for agricultural practices, thirty two (17.1\%) agreed and sixteen of respondents (8.6\%) were undecided. Eighty-nine (47.6\%) respondents were for the idea that livestock keeping and crop farming be encouraged rather than conservation, while fiftytwo $(27.8 \%)$ opted conservation and forty-six (24.6\%) were undecided. Seventy-eight (41.7\%) of the respondents agreed that current conservation area is inadequate and should be increased in size, eighty-one $(43.3 \%)$ disagreed while twenty eight $(15 \%)$ were undecided.

\section{Attitudes and Perceptions of Wildlife Conservation}

The findings revealed that the attitudes of the local people towards wildlife conservation were independent of sex and conservation knowledge. There is a significant difference in the relationship between the age of the respondents and attitudes $\left(\chi^{2}=23.036, \mathrm{df}=6, \mathrm{P}=0.001\right)$. The young respondents were more positive towards conservation. The age also significantly affected perceptions of the benefits from the reserve $\left(\chi^{2}\right.$ $=14.398, \mathrm{df}=2, \mathrm{P}=0.001)$. Majority of young respondents were elite and informed on both tangible and non-tangible benefits. The level of education significantly affects the respondent's attitudes on whether a conservation area is inadequate and should be increased in size $\left(\chi^{2}=10.250, \mathrm{df}=3, \mathrm{P}=0.017\right)$. Those respondents who attained formal education appreciate value of conservation area. The economic activities significantly affect the attitudes of the respondents whether conser-vation be encouraged rather than crop farming and livestock keeping $\left(\chi^{2}=15.816, \mathrm{df}=6, \mathrm{P}=0.015\right)$. Subsistence farmers are most affected by land allocated to the reserve and damages caused by wildlife. In addition, there is significant difference between the economic activities and conservation area is inadequate and be increased in size $\left(\chi^{2}=13.675, \mathrm{df}=2, \mathrm{P}=0.033\right)$. Farmers and herders do not support increase in the size of conservation area relative to those who are engaged in non-farming activities.

There is a significant difference in relationship between wildlife benefits and attitudes on conservation were waste of land $\left(\chi^{2}=8.308, \mathrm{df}=1\right.$, $\mathrm{P}=0.004)$. Those respondents who gained benefits had positive attitudes towards conservation area. There were also significance difference in the relationship between wildlife damage and economic activities $\left(\chi^{2}=9.815, \mathrm{df}=2, \mathrm{P}=0.007\right)$. Crop farmers are most affected compared to herders and least reported among those engaged in other economic activities. There were significance differences in the relationship between proximity of the respondent's residence to the reserve and attitudes whether conservation be encouraged rather than livestock keeping or farming $\left(\chi^{2}=17.252, \mathrm{df}=6, \mathrm{P}=0.008\right)$. Those adjacent to the reserve incur more damage caused by large animals and associate the reserve with problem animals especially elephants and baboons. The result showed that there was no significant 
relationship between the distance of the respondents' residence to the reserve and damages caused by wildlife. Those residing in far distance from the reserve boundary are also affected by wildlife damage but those caused by small-bodied animals.

There were significant difference in the relationship between wildlife damage and attitudes on whether conservation be encourag-ed rather than livestock keeping and crop farming $\left(\chi^{2}=9.272\right.$, $\mathrm{df}=1, \mathrm{P}=0.002)$. Those who incur damage have negative attitudes and willing for conversion of the conservation area into livestock and crop farming. There is a significant relation-ship between restriction in wildlife resource use and attitudes on whether conservation be encouraged rather than livestock keeping or farming $\left(\chi^{2}=9.153\right.$, $\mathrm{df}=2, \mathrm{P}=0.010)$. Those respondents restricted access to resources viewed it negatively and blames the management of the reserve for claims of resources.

\section{DISCUSSION}

\section{Demographic and Socio-economic Profile of Respondents}

The results showed majority of the respondent's held negative attitudes towards MNR. These are attributed to high levels of illiteracy, increased number of crop farmers, low participation in conservation awareness programs and past experience of human wildlife conflicts. The findings further showed sex had no effect on the attitudes of the respondents. These findings conform to those of past studies (Akama et al. 1995; Fiallo and Jacobson 1995; De Boer and Baquete 1998; Infield 1998). They concur that there is no significant relationship between sex and attitudes. Similarly, conservation awareness issues had no significant difference in attitudes and perceptions of respondents'. This differs with findings by Newmark et al. (1993); Fiallo and Jacobson (1995). They found conser-vation knowledge and awareness significantly affected attitudes and perceptions towards protected area conservation.

Age has significantly influenced attitudes and perceptions of the local communities towards conservation area. This finding is similar to observed relationship between age and respondents attitudes as found by Kimeli (1996). The young generation agreed that protected area was inadequate and therefore should be increased in size. Similarly, results indicated that older respondents were less likely to support the reserve than younger people. The respondents' age was associated with the length of experience with wildlife benefits and their associated cost where older respondents' were more likely to have been adversely affected by the wildlife damages and restriction in their use associated with the reserve's establishment than younger respondents'. These results were similar to those reported for older residents in five protected areas in Tanzania, where findings revealed that they were more likely to support the abolition of protected areas than young residents (Newmark et al. 1993). Similarly, Fiallo and Jacobson (1995) found that age significantly affected the attitudes where residents over 54 years old were less likely to feel positively towards the reserve than middle-aged people. The later had divided opinions and people under 40 years old were more likely than their elders to support the reserve.

The level of formal education associated with respondent's age influenced attitudes. The younger residents tended to have higher education levels than older respondents because of the formers had access to education than their counterparts who lived in the past. The educated people may have more knowledge on conservation related issues which could have resulted from high level of interaction at learning or educational institutions and exposures with media. Further positive change may be attributed to the greater opportunity to gain benefits from the reserve through non-agricultural employment among educated persons since they are less likely to be living at the margin of subsistence. These findings concur with those at Kossi Tappu wildlife reserve in Nepal, where respondents with higher household literacy rates had positive attitudes towards the reserve (Heinen 1993). They are also similar to findings by Akama et al. (1995), they reported as the level of education increases, the level of negativity towards the reserve decreases. The findings further concur with those observation made by Infield (1988), Fiallo and Jacobson (1995). However, De Boer and Baquate (1998) in their study found that education level had no significant effect on attitudes. It can be inferred that a society with high percentage of educated people may have high level of awareness than those with low level of education to influence positive attitudes. 


\section{Local Perceptions of Wildlife Cost and Benefits Associated with MNR}

Those respondents who incur wildlife damage had more negative attitudes relative to those who incur fewer damages. These include crop damage, livestock depredation and loss of human life. The damages were due to increased farm encroachment and settlements into wildlife migratory corridors and dispersal areas. It is also due to limited number of rangers involved in guarding and control of problem animals and inadequate strategy to mitigate human-wildlife conflicts, especially elephants. Most of the methods currently in use fail to resolve conflict and caused difficulties implementation of Problem Animal Control.

Local communities are not compensated for the wildlife property damages except human death and injuries similar to many other developing countries. Local communities perceive wildlife as state property and have negative attitudes towards them. This may also attributed to low level of vigilance by local communities where those who commit their time guarding farms and livestock against wildlife attack experienced less wildlife damages. Similarly, source of species causing crop damages influenced attitudes concerning the reserve since local communities associate the reserve with wildlife. These findings concur with those of Parry and Campbell (1992), De Boer and Baquate (1998) and Infield (1998).

The findings on the proximity of respondents' residence to the reserve have significant effect on the attitudes held by individuals. This implies that local communities adjacent to the reserve have negative attitudes compared to those who are far away and agrees with findings in Napal by Studsrod and Wegge (1995). Local communities adjacent to the reserve suffer from large-scale damages by elephants and baboons but those far from the reserve experience damages by smallbodied animals such as birds, mangoose and honey badgers. The adjacent community experience more direct cost resulting from wildlife damage compared to those who are far away from the reserve boundary. This cost includes human injuries, livestock depredations, crop damages, loss of human life and grazing land while those who are far from the reserve had less direct cost and experienced more benefits.

In the study area guarding strategies are ineffective against large animals for fear of attack and local communities perceive wildlife guarding as the responsibility of KWS. They accept responsibility to manage small-bodied problem animals. These results concurred with those of previous studies done in Tsavo and Nairobi national parks by Akama et al. (1995) and Sumatra by Linkie et al. (2007). They both agreed that perceptions of local communities living adjacent to the protected area are affected by severity of damage. The findings provide substantial evidence that proximity of the respondents' to the reserve has significant effect on attitudes and perceptions. Findings of this study are similar to those reported in Maasai Mara Game Reserve by Ngary (1995) but differ with those of De Boer and Baquate (1998).

The findings showed that economic activities of respondents affect attitudes and perceptions of local communities towards wildlife conservation. With small-scale crop farmers being affected most, hence posses negative attitudes relative to those respondents engaged in other occupations. Wildlife damage crops, threatens lives and lost fertile land to the reserve while those respondents engaged in non-farm activities favor conservation compared to those who depended solely on crop production for their livelihood option. Similarly, Akama et al. (1995) found negative attitudes with crop farmers than those involved in other economic activities and those who perceive no value for themselves from PAs in a view of the loses they incur due to wildlife damages. This study also concurs with the results of Infield (1998) and Newmark et al. (1993).

The benefit accrued and personal returns from wildlife related enterprises positively affected attitudes and perceptions of the respondents. The findings concur with Gilligham and Phyllis (1999) and Romanach et al. (2007). The local communities perceive the reserve as a liability. Individual and community cost of wildlife conservation far exceeds the benefits. Most of the revenues from the reserve are generated to the National Government and the tourism industry. Moreover, very little of this revenue were spent on economic development or services for the affected local communities. Similarly, local communities who perceive personal benefits from the reserve held more positive attitudes towards it. Similar situations have been reported in other PAs around the world. Infield (1998) found that households that benefits from the reserve have positive attitudes towards conservation than household that did not in Natal, South Africa.

On the contrary, according to Parry and 
Campbell (1992) local communities in northern Botswana held negative attitudes towards wildlife in spite of the benefits they received from employment and exploitation of wildlife resources. In most parts benefits perceived was small in relation to losses and were inadequate to off set cost of living with wildlife. Similar findings was reported elsewhere by Western (1984) in Amboseli National Park, who described how economic benefits were shared with the local communities and Homewood et al. (1997) concur with this sentiment. However, Njumbi (1994) contradicts it after performing a survey at Kimana ranch in Amboseli, Kenya and showed that revenue sharing was highly appreciated by the individual members of group ranch. Therefore, perceived personal benefits must outweigh perceived disadvantages to engender positive attitudes towards conservation as suggested elsewhere by Fiallo and Jacobson (1995).

\section{Attitudes and Perceptions of Wildlife Conservation}

The restricted use of wildlife resources has significant effect on the attitudes and perceptions of local communities. The findings concur with De Boer and Baquate (1998), particularly, on the conservation as a waste of land. The respondents regard establishment of the reserve a foreign concept, which imposes greater restrictions on resource use by local communities to which they have informal right of tenure. The loss of land by the local communities may have consequences for them who depend on it for resources such as fuel wood, key grazing area during drought and source of water. They claim access to the reserve and perceived being denied where exploitation of natural resources allowed. The forest support livelihoods and evidenced by mean capital fuel consumption of $1500 \mathrm{kgy}^{-1}$ required by the household in the study area (Kirubi et al. 2000). This may be estimated high but access is regulated through permits that restrict wood fuel consumption patterns.

Similarly, during the establishment of MNR local communities' were promised alternative uses to support the concept but to date this was not achieved. Thus, local communities adjacent to MNR view it as a liability and have negative attitudes towards the reserve as a whole and wildlife in particular.

\section{CONCLUSIONS AND RECOMMENDATIONS}

In this study combination of different factors that shape local communities attitudes and perceptions towards the reserve was identified and their effects analyzed in order to win local support for the conservation of wildlife.

The result provided basis for improvement of protected area management and design management strategies to improve incorporation of local communities into long-term strategies for sustaining MNR. The selected socio-economic factors such as age, level of education, economic activities, wildlife benefits and damages and distance of respondents' residents from the reserve affect attitudes and perceptions of local communities. Those who were young, engaged in non-crop activities, attained a higher level of formal education and had gained benefits tended to have more positive attitudes towards wildlife conservation. Therefore, to foster partnership with adjacent community and successfully implement conservation it is important to consider these factors in MNR as well for those protected area challenged by similar scenario. Sex and conservation awareness played minimal to affect resident's attitudes and perceptions. It is important to identify, test and validate wildlife deterrence methods and alternative land use options to increase return per unit land and reduce crop damage. The technique will integrate indigenous and conventional strategies. The findings further suggest need to initiate long term monitoring to analyze trends in the incidences of human-wildlife conflicts especially those caused by elephants and baboons in MNR.

\section{ACKNOWLEDGEMENT}

I would like to thank Drs. Karanja G.G., Ipara H., Odanga J., Sitati N. and Wahungu G. for their critical analyses during preparation of manuscript. The contribution by anonymous reviewer greatly improved on the manuscript.

\section{REFERENCES}

Akama J, Lant C, Burnet D 1995. Conflicting attitudes towards state wildlife conservation programme in Kenya. Society and Natural Resources, 8: 133-144.

De Boer W, Baquate D 1998. Natural resource use, crop damage and attitudes of rural people in the vicinity of the Maputo Elephant Reserve, Mozambique. Environmental Conservation, 5(3): 208-218. 
DRSRS 1996. Department of Resource Survey and Remote Sensing; Land use mapping of Kenya using remote sensing techniques. Nairobi: DRSRS.

Fiallo E, Jacobson S 1995. Local communities and protected areas: attitudes of rural residents towards conservation and Machililla National Park, Ecuador. Environmental Conservation, 22(3): 241-9.

Gilligham S, Phyllis C 1999. The impact of wildlife related benefits on the conservation attitudes of local people around the Selous Game Reserve, Tanzania. Environmental Conservation, 26(3): 218-228.

GoK 1999. Government of Kenya, the Population and Housing Census. Counting Our People For Development. Vol. I. Nairobi; Government Printer,

Grove R, Anderson H 1987. The scramble for Edin: Past, Present and Future in African conservation. In: D Anderson, R Grove (Eds.): Conservation in Africa: People, Policy and Practice. Cambridge; Cambridge University Press, pp. 1-12.

Heinen J 1993. Park-People relations in Kossi Tappu wildlife reserve, Nepal: A socio-economic analysis. Environmental Conservation, 20: 25-34.

Homewood K, Kiwasita H, Brockington D 1997. Conservation with Development in East African Range Lands: The Case of Mkomazi Game Reserve, Tanzania. Unpublished report. London: Department of International Development, Economic and Social Committees on Research, P. 105.

Hough J 1988. Obstacles to effective management of conflict between national parks and surrounding human communities in developing countries. Environmental Conservation, 15(2): 129-36.

Infield M 1998. Attitudes of rural community towards conservation and a local conservation area in Natal, South Africa. Biological Conservation, 45: 21-46.

IUCN/UNEP 1987. International Union of Conservation of Nature and Natural Resources/UNEP. Ecologically Sensitive Site in Africa. Washington, DC: World Bank.

Kimeli W 1996. Non-Use Values as a Key Factor in the Conservation of Biodiversity. Unpublished Project Report. Eldoret: Moi University.

Kirubi C, Wamicha N, Laichena J 2000. The effects of wood fuel consumption in the ASAL areas of Kenya: the case of Marsabit forest. African Journal of Ecology, 38: 47-52.

KWS 1994. Wildlife-human Conflicts in Kenya. Nairobi: Jacaranda Designs Limited.

Leitoro M, Nicholas A, Masinde P 1994. Elephant and Large Mammal Population. Unpublished report. Nairobi: KWS

Linkie M, Dinata Y, Nofrianto A, Leader-Williams 2007. Patterns and perceptions of wildlife crop raiding in and around Kerinci Seblat National Park, Sumatra. Animal Conservation, 10: 127-135.

Lusigi W 1981. New approaches to wildlife conservation in Kenya. Ambio, 6: 87-92.
Lusigi W. 1994. Socio-economic and ecological prospects for the multiple use of protected areas in Africa. In: M Munasinghe, J McNeely (Eds.): Protected Area Economics and Policy. Washington DC: World Bank. MALDM 1995. Ministry of Agriculture, Livestock Development and Marketing; Range Management Handbook of Kenya, Vol. II. Nairobi: Government Printer.

Mishra H 1994. A delicate balance: tigers, rhinoceros, tourists and park management Vs the needs of the local people in Chitwan National Park, Nepal. In: J McNeely, K Miller (Eds.): National Parks, Conservation and Development. The Role of Protected Areas in Sustaining Society. Washington DC: Smithsonian Press.

MPND 1994. Ministry of Planning and National Development, Marsabit Development Plan (199496). Nairobi: Government Printer.

Newmark W, Leonard N, Gamassa D, Seriko H 1993. Conservation attitudes of local communities living adjacent to five protected areas in Tanzania. Biology of Conservation, 63: 177-183.

Ngary SM 1995. The Economic Impact of Livestock Depredation in the Dispersal Areas of Masaai Mara Reserve. Unpublished M. Phil. thesis. Eldoret: Moi University.

Njumbi S 1994. Effects of Poaching on the Population Structure of Elephants in Meru National Park. M. Phil. Thesis, unpublished. Eldoret: Moi University.

Parry D, Campbell B 1992. Attitudes of the rural communities to animal wildlife and its utilization in Chobe enclave and Mababe Depression, Botswana. Environmental Conservation, 19(3): 245-52.

Romanach SS, Lindsay A, Woodroffe R 2007. Determinants of attitudes towards predators in central Kenya and suggestions for increasing tolerance in livestock dominated landscape. Oryx, 4(2): 185-195.

Soto B, Munthali SM, Breen C 2001. Perceptions of the forestry and wildlife policy by the local communities living in the Moputo elephant reserve, Mozambique. Biodiversity and Conservation, 10: 1723-1738.

SPSS 1998. Statistical Package for Social Sciences (SPSS): Advanced Statistics Version 11.5. Chicago: SPSS Inc.

Studsrod J, Wegge P 1995. Park-People relationships: the case of damage caused by park animals around the royal Bardia National Park, Nepal. Environmental Conservation, 22: 133-42.

Wells M 1996. The role of protected areas in the new South Africa. Environmental Conservation, 23 (4): 322-331.

Western D 1994. Amboseli National Park: Human values and the conservation of Savana ecosystems. In: JA McNeely, KR Miller (Eds.): National Parks, Conservation and Development. Washington DC: Smithsonian Press. 